\title{
The Children and Young People's Improving Access to Psychological Therapies (CYP IAPT) Programme in England
}

\begin{abstract}
Peter Fonagy, Research Department of Clinical, Educational and Health Psychology, UCL; Chief Executive, The Anna Freud Centre; National Clinical Lead, Children and Young People's Improving Access to Psychological Therapies Programme
\end{abstract}

Kathryn Pugh, Children and Young People's Mental Health Programme Lead, NHS England Anne O'Herlihy, Children and Young People's Mental Health Project Manager, NHS England

Correspondence to: Peter Fonagy, Research Department of Clinical, Educational and Health Psychology, University College London, 1-19 Torrington Place, London WC1E 7HB, UK. E-mail: p.fonagy@ucl.ac.uk

\section{INTRODUCTION}

The Children and Young People's Improving Access to Psychological Therapies (CYP IAPT) programme was initiated in 2011 by the Department of Health [1]. It aimed to improve the access of children, young people and their families to evidence-based psychological therapies (EBPTs) and to seek their participation in developing a new and collaborative service.

CYP IAPT benefitted from lessons learned from the earlier implementation of the adult IAPT programme - a programme described as the most extensive and centralised attempt to implement EBPTs [2]. This had focused on widening the availability of EBPTs to adults with depression and anxiety (see [3]). CYP IAPT had a more extensive focus, aiming to address the broad range of mental health difficulties commonly presenting to communitybased Child and Adolescent Mental Health Services (CAMHS). The formalised framework for implementation of CYP IAPT was published in 2012 [4]. Government funding of $£ 52$ million covered the initial four-year implementation period. The aim was to transform CAMHS into an evidence-based, outcome-focused, collaborative service. However, 
successful implementation of CYP IAPT required an understanding of the challenges then facing CAMHS, alongside an implementation strategy designed to address them.

\section{Challenges facing CAMHS}

Numerous inquiries into CAMHS [e.g., 5] had identified problems with service structure and treatment delivery. In brief, service user and referrer accounts pictured an inaccessible service, with lengthy waiting lists, inflexible diagnostic entry requirements, and limited involvement of carers and young people in decision making. Services were seen as stigmatising, especially for minority groups. Interventions were lengthy. Preventive and resilience-building treatments were largely absent, as was national data to enable monitoring of service effectiveness and to support planning. For fuller discussions, see Chapter $\mathrm{X}-$ Bruce/Dowdney and [6].

CAMHS staff attributed service shortcomings to a significant shortage of adequately trained professionals, alongside vacant posts and redundancies. Consequently, few services could offer self-referral routes, and support was often lacking for clients transitioning between child and adult services, or needing referral across other NHS or agency boundaries. There were also insufficient resources for monitoring and evaluation of individual and service performance [Chapt X - Bruce/Dowdney]. These difficulties were set against a background of rising rates in community mental health problems alongside increasing referrals $[7,8]$. Nonetheless, only between one-quarter and one-third of those with mental health problems found their way to mental health services, while in adolescent males the proportion was thought to be below $15 \%$ [9].

\section{IMPLEMENTATION}


Addressing the above challenges and delivering this ambitious programme involved the support of service and commissioner partnerships, educational collaboratives and a series of implementation initiatives. There was no template for a CYP IAPT service - rather, there was a phased dissemination of a set of clinical principles (an outcome focus, increased patient and parent participation and the use of EBPTs) implemented through local partnerships and collaborations across a range of services [10].

The programme took advantage of pre-existing CAMHS partnerships between public commissioners of mental health services and the NHS, Local Authorities and the Charity and Voluntary sector service providers (in this chapter to be known as Commissioner and Provider Service partnerships - CPSs). These partnerships, in some form, had built up over the previous six years. Together these bodies would be responsible for the delivery of CYP IAPT. For full details of the implementation process, see [11].

\section{Partnerships and Collaboratives}

The initial implementation stage required CPSs to work with training providers based in Higher Education Institutions (HEIs) to establish CYP IAPT Learning Collaboratives. Thirteen potential collaboratives applied to deliver the programme, and three were chosen in the first year through a competitive process. The selection was made on the basis that they were ready to make the necessary service culture change; to initiate training of managers and supervisors; to ensure services were ready to support the delivery of EBPTs and to gather routine outcome monitoring $(\mathrm{ROM})$ data. These partnerships were to implement a coherent set of principles governing service organisation and delivery and, over time, become countrywide. 
Partnerships worked closely and iteratively with the HEIs to implement a national curriculum developed by expert consensus, using a modular approach $[12,13]$. This approach recognises that children present with multiple problems and disorders, that treatment needs to evolve within episodes of care, and that practitioners require expertise in many EBPT protocols.

\section{$\underline{\text { Implementation Initiatives }}$}

Five systematic and interdependent initiatives were implemented. These covered the delivery of training to clinical staff, clinical service leaders and service managers. Other initiatives focused on developing and implementing a model of genuine user participation and collaborative relationships with service staff.

Training initiatives: Two initiatives focused on training. The first concentrated on training CAMHS staff in two NICE-approved EBPTs - cognitive-behavioural therapy (CBT) for anxiety and depression, and parent training for conduct problems. Two years later, training extended to systemic family practice for depression, self-harm, conduct disorder and eating disorders; and interpersonal psychotherapy for young people with anxiety or depression. In its third year, the programme included training in the basic principles of EBPT to less wellqualified practitioners using a curriculum that incorporated e-learning via an internet-based resource (MindEd e-learning - see Internet Resources). The second initiative focused on managers and service leaders within participating CSPs who were concurrently trained in service change, demand and capacity management, and leadership. Training was also provided to senior clinicians providing supervision in EBPT, and in monitoring outcomes to newly trained therapists. 
User participation initiatives: User participation was the focus of the remaining initiatives that aimed at delivering genuine, and empowering, user participation at different service levels. Firstly, children/young people and their families became involved in service design and delivery at both national and local levels. They also participated in service staff training events organised by the Learning Collaboratives. Secondly, CPSs were required to set up easily accessible and convenient mechanisms to enable children/young people and their carers to self-refer. Thirdly, on entering the service, users were empowered by becoming involved in the choice of treatment, in formulating their individual therapeutic goals, and by participating in routine session-by-session feedback on symptoms, treatment progression, and satisfaction. User participation, alongside ROM data of this kind, has been shown to have therapeutic and service effectiveness benefits - see e.g. [14, 15].

Such user empowerment was seen as an essential part of CYP IAPT. Developing services based on a spirit of collaborative care and trust was particularly important for the largely socially disadvantaged children and young people who attend CAMHS, whose previous experiences of healthcare are likely to have made them suspicious of both the motives of others and the information they impart. The transformed services sought to offer a different set of experiences based on the belief that experiencing their therapists think about them and respond to their preferences, thoughts and feelings would enhance young people's capacity to absorb and respond to information both in therapy and in their wider social world [16].

Monitoring user participation and training initiatives: In CYP IAPT, mandatory ROM measures of user participation typically take the form of standardized questionnaires used before each treatment session to gauge the severity of the patient's problems, their sense of progress towards their goals, and the extent to which their expectations of treatment were 
met. The effectiveness of staff training is monitored via staff supervision, ROM feedback data and videotaping of trainees' performance in the workplace. This combination facilitates treatment fidelity, immediate feedback and opportunities for trainee practice repetition. It assists in avoiding biases that can affect trainees' learning - such as confirmatory and hindsight basis [17]. It also aids trainees and supervisors to develop detailed plans for improvement. During implementation, the close collaboration of trainers at the HEIs, clinical supervisors, service leaders and the central CYP IAPT implementation team is critical in ensuring that high standards of competence are reached.

\section{SERVICE DEVELOPMENT OUTCOMES}

At the beginning of 2016, year 5 of CYP IAPT, there were 94 CPSs covering 82\% of 0-19 year olds nationally. Within these, by 2015, 372 therapists, 86 supervisors and 51 service leaders had been trained. National coverage is expected to be $100 \%$ by 2018 .

Successful user participation has been a major achievement. It led to initiatives such as the development of a Mental Health Services Passport held by young people and carers (see Internet Resources). These are written jointly by young people and practitioners. They contain a summary of service users' issues, history and preferences. A further initiative commissioned a young people's mental health charity (YoungMinds) to facilitate user contributions to service design and delivery, to establish a network for parents and carers, and develop a resource toolkit for service users, commissioners and providers ('Parents Say' see Internet Resources).

Quality frameworks for the accreditation of CYP IAPT training courses and services have been developed by the newly formed National Accreditation Council [18]. From 2016, the 
outcome measures developed to support CYP IAPT will be incorporated into the mandatory Mental Health Services Data Set (MHSDS).

\section{EVALUATION}

A full audit of service and user outcomes has not been possible due to difficulties beyond the scope of the programme in developing an accessible computerised system for recording a full national minimum data set. Nonetheless, based on the measures available, an internal audit revealed a number of achievements. The audit derives from interviews with 92 staff, 45 children/young people and 42 parents. Informants came from 12 CSP partnerships covering 6,803 children/young people, 11 services and 43 clinical teams [19] .

Improved access and efficiency: Between 2010 and 2014, the time between referral and first appointment decreased by $75 \%$ (from 239 to 64 days) and the average time between referral and assessment decreased by $21 \%$ to 235 days. Staff attributed these improvements to the use of ROM. Service accessibility improved via new self-referral routes, single points of access, outreach services and evening and weekend appointments. The average number of selfreferrals increased by $195 \%$.

Evidence-based interventions: $83 \%$ of clinicians trained in NICE-recommended therapies were continuing to provide them and receive related supervision. They expressed increased confidence in choosing and delivering an EBPT. Nonetheless, a substantial proportion of young service users were still not receiving the recommended evidence-based treatment.

ROM and user engagement: ROM increased and facilitated shared decision-making. Users saw it as helping to 'keep things focused'. There was increased service user participation in 
service organization and management, including staff appraisal and selection. Improved user engagement was reflected in an increase of $22 \%$ in the proportion of cases closed by mutual agreement.

Challenges to implementation: Concurrent cost efficiency initiatives, competing organisational changes and contract tendering processes substantially disrupted the implementation of CYP IAPT at some sites. Staff morale was negatively affected as increased referrals occurred alongside staffing reductions and time lost to training. Insufficient time was provided to embed new practices and to learn new systems and processes. ROM generated some anxiety among practitioners, particularly when service users did not report positive change. As noted above, there were programme failures in information governance and technology.

Both adult IAPT services and the CYP IAPT transformation programme have their critics who share, e.g., concerns over what they regard as an over-medicalised diagnostic focus and a therapeutic reliance on a traditional CBT approach $[20,21]$. However, CYP IAPT training curricula developments have resulted in many more systemic family practitioners, interpersonal psychotherapists and parenting therapists than CBT therapists [10]. It has also been suggested that IAPT therapeutic interventions are constrained by unrealistic time limits and an over-focus on the targets and measures needed for contract tendering purposes [20, 21]. Against this needs to be set the CYP IAPT audit data outlined above, and also other qualitative feedback from the same data set. This indicates that $61 \%$ of clinicians thought that service access had improved for their local population; well over half reported often or always using outcome data to review or inform therapy; and more than three-quarters reported frequent engagement in shared decision-making activities with all service users [10]. 


\section{FUTURE DIRECTIONS}

CYP IAPT is the foundation for a wider continuous transformation process in CAMHS [22].

New funding will create a nationwide programme based on CYP IAPT principles, with training extended to include community-based eating disorder services, perinatal care, service users with learning disabilities and those with an autism spectrum disorder. The number of EBPTs will continue to widen and will include counselling and psychopharmacological treatments, with supportive curriculum initiatives to educate clinicians in these approaches and provide the developmental understanding needed in the $0-18$ age range.

\section{References}

1. Department of Health. Talking therapies: A four-year plan of action. London, UK: Department of Health; 2011. Available from: https://www.gov.uk/government/uploads/system/uploads/attachment_data/file/213765/dh_12 3985.pdf.

2. McHugh RK, Barlow DH. The dissemination and implementation of evidence-based psychological treatments. A review of current efforts. American Psychologist. 2010;65(2):7384. doi: 10.1037/a0018121.

3. Layard R, Clark D. Thrive: The power of evidence-based psychological therapies. London, UK: Allen Lane; 2014.

4. Centre for Mental Health, Department of Health, Mind, NHS Confederation Mental Health Network, Rethink Mental Illness, Turning Point. No health without mental health: Implementation framework. Crown copyright; 2012. Available from: https://www.gov.uk/government/uploads/system/uploads/attachment_data/file/216870/NoHealth-Without-Mental-Health-Implementation-Framework-Report-accessible-version.pdf. 5. Kennedy I. Getting it right for children and young people. Overcoming cultural barriers in the NHS so as to meet their needs. Independent review. Crown Copyright; 2010. Available from:

http://www.dh.gov.uk/prod_consum_dh/groups/dh_digitalassets/@dh/@en/@ps/documents/d igitalasset/dh_119446.pdf.

6. McGorry P, Bates T, Birchwood M. Designing youth mental health services for the $21 \mathrm{st}$ century: Examples from Australia, Ireland and the UK. British Journal of Psychiatry Supplement. 2013;54:s30-5. doi: 10.1192/bjp.bp.112.119214.

7. Bor W, Dean AJ, Najman J, Hayatbakhsh R. Are child and adolescent mental health problems increasing in the 21st century? A systematic review. Australian and New Zealand Journal of Psychiatry. 2014;48(7):606-16. doi: 10.1177/0004867414533834.

8. NHS Benchmarking Network. CAMHS Benchmarking Report 2015. Manchester: NHS Benchmarking Network; 2015. 
9. Green H, McGinnity A, Meltzer H, Ford T, Goodman R. Mental health of children and young people in Great Britain, 2004. A survey carried out by the Office for National Statistics on behalf of the Department of Health and the Scottish Executive. Basingstoke, UK: Palgrave Macmillan; 2005. Available from: http://www.esds.ac.uk/doc/5269/mrdoc/pdf/5269technicalreport.pdf.

10. Fonagy P, Clark DM. Update on the Improving Access to Psychological Therapies programme in England: Commentary on ... Children and Young People's Improving Access to Psychological Therapies. BJPsych Bulletin. 2015;39(5):248-51. doi:

10.1192/pb.bp.115.052282.

11. Fonagy P, Myles P, Pugh K, Shafran R. Transformation of mental health services for children and young people in the UK. In: Beidas RS, P.C.Kendall, editors. Child and adolescent therapy: Dissemination and implementation of empirically supported treatments. New York, NY: Oxford University Press; 2014. p. 158-78.

12. Chorpita BF, Bernstein A, Daleiden EL. Empirically guided coordination of multiple evidence-based treatments: An illustration of relevance mapping in children's mental health services. Journal of Consulting and Clinical Psychology. 2011;79(4):470-80. doi: 10.1037/a0023982.

13. Weisz JR, Chorpita BF, Palinkas LA, Schoenwald SK, Miranda J, Bearman SK, et al. Testing standard and modular designs for psychotherapy treating depression, anxiety, and conduct problems in youth: a randomized effectiveness trial. Arch Gen Psychiatry. 2012;69(3):274-82. doi: 10.1001/archgenpsychiatry.2011.147.

14. Miller SD, Hubble MA, Chow D, Seidel J. Beyond measures and monitoring: Realizing the potential of feedback-informed treatment. Psychotherapy (Chic). 2015;52(4):449-57. doi: 10.1037/pst0000031.

15. Bickman L, Kelley SD, Breda C, de Andrade AR, Riemer M. Effects of routine feedback to clinicians on mental health outcomes of youths: Results of a randomized trial. Psychiatric Services. 2011;62(12):1423-9. doi: 10.1176/appi.ps.002052011.

16. Fonagy P, Allison E. The role of mentalizing and epistemic trust in the therapeutic relationship. Psychotherapy (Chic). 2014;51(3):372-80. doi: 10.1037/a0036505.

17. Tracey TJ, Wampold BE, Lichtenberg JW, Goodyear RK. Expertise in psychotherapy: An elusive goal? American Psychologist. 2014;69(3):218-29. doi: 10.1037/a0035099. 18. York A, Kingsbury S, Rayment B, Fleming I, Thompson P, Hemsley M, et al. "Delivering with and delivering well". CYP IAPT principles in Child \& Adolescent Mental Health services. Values and standards. London, UK: CAMHS Press; 2013. Available from: https://www.england.nhs.uk/wp-content/uploads/2014/12/delvr-with-delvrng-well.pdf. 19. Edbrooke-Childs J, O’Herlihy A, Wolpert M, Pugh K, Fonagy P. Children and Young People's Improving Access to Psychological Therapies: Rapid internal audit national report. London: Evidence-based Practice Unit, the Anna Freud Centre and UCL; 2015. 20. Binnie J. Do you want therapy with that? A critical account of working within IAPT. Mental Health Review Journal. 2015;20(2):79-83. doi: 10.1108/mhrj-11-2014-0044.

21. Timimi S. Children and Young People's Improving Access to Psychological Therapies: Inspiring innovation or more of the same? BJPsych Bulletin. 2015;39(2):57-60. doi: 10.1192/pb.bp.114.047118.

22. Department of Health. Future in mind: Promoting, protecting and improving our children and young people's mental health and wellbeing London: NHS England; 2015. Available from:

https://www.gov.uk/government/uploads/system/uploads/attachment_data/file/414024/Childr ens_Mental_Health.pdf. 


\section{Internet Resources}

NHS England: Information about the CYP IAPT programme, with links to useful resources including the Mental Health Services Passport.

https://www.england.nhs.uk/mentalhealth/cyp/iapt/ (last accessed February 2016)

MindEd e-learning: A resource for the MindEd curricula in children's/young people's mental health. https://www.minded.org.uk/mod/page/view.php?id=1259 (last accessed February 2016)

Mental Health Services Passport: Details of the 'passport'-style brief of key facts for children/young people using CAMHS.

https://www.england.nhs.uk/mentalhealth/2015/10/15/passport-brief-yp-mh (last accessed February 2016)

Parents Say: Information about YoungMinds' 'toolkit' to support CAMHS to implement and encourage parent participation in all aspects of their work.

http://www.youngminds.org.uk/psaytoolkit (last accessed February 2016) 